https://doi.org/10.48009/2_iis_2006_192-196

\title{
E-COMMERCE TRANSACTIONS: AN EMPIRICAL ANALYSIS \& UNDERSTANDING OF WEB-BASED APPLICATIONS
}

\author{
Ephrem Eyob, Virginia State University, eeyob@vsu.edu
}

\begin{abstract}
In this era of diverse technology applications and use of fast computers, information systems play a paramount role in the day-to-day operations for most organizations and by extension for individuals working in these organizations. The trend is to move away from traditional marketing and selling by offering customers products and services through an alternative channel: e-commerce. Important issues arise on how to assess e-commerce business models, how the customers feel about products and services offered, and the overall effectiveness of business transactions through e-commerce. This research paper addresses related issues on data collected by an independent Internet performance management company on availability of Web sites and transaction speed on selected companies.
\end{abstract}

Keywords: E-Commerce, Web Effectiveness, Web Application

\section{INTRODUCTION}

Whenever Web/Internet applications performance is covered, then invariably, the focus shifts to dimensions of quality and customer satisfaction [7]. Evaluating performance of Web sites is difficult [9]. Web server performance can be controlled automatically by using specialized algorithms [5]. Murthy [8] investigated the effects of different types of application controls on e-commerce performance. This research investigates the effects of the following attributes on the overall performance of e-commerce transactions:

- Web services which deal with accessibility and the capacity of serving the clients;

- Web services availability related to the readiness of the Web site for immediate service;

- Web services interoperability related to the developmental environments used to implement services and the plethora of programming languages or operating systems through which the service is hosted;
- Web services security related to the overall security of the Web and keeping the transaction free from hackers, saboteurs, and spies.

With the increase in the use of Web services, which are delivered over the public Internet, security of the systems is a growing concern. Quality of Service $(Q o S)$ for Web Services is about bringing business value to service providers by guaranteeing a secure competitive edge in their ease of adoption and implementation. Other related issue to Web services and quality of services is speed, which is based on the detailed activities related to processing when using Web information technology. Rada et. al, [6] analyzed the World-Wide Web standards and information systems effectiveness. A new mechanism for linking webs and the standards raises issues related to computer ethics. The nature and social impact of computer technology and the corresponding formulation and justification of policies for ethical use of such technology is a driving force for technologist thought process . Again the question of the relationship between speed and quality of service becomes important. As a result the sophistication of posted Web documents has grown, so has the demand for more powerful languages for structuring and presentations.

Web applications are increasingly a platform of choice for complex business software and online services; it remains a challenge to ensure that the Web application is easy, efficient, and effective for users, especially people with disabilities. Accessibility requires that users, including users with disabilities, are able to use the applications effectively and with a reasonable amount of effort. Although there has been important progress in recent years in describing the relationship between architecture and usability, architectural support for accessibility has not been adequately addressed. Hoffman et. al, [3] describe common accessibility problems encountered in Web applications and explain how architecture can help address these problems through reusable accessible objects, supplementing information in links, buttons, and labels, assisting in access to Web page visual information, handling errors, and providing time-out notification and recovery. Accessibility and usability provide access to on-screen sign posting, which 
refers to Web page visual information that communicates the title of the application and page, any essential system messages, and any feedback or status messages. Another web services factor that influences the quality is to have a time-out function. This is intended to limit the risks that may occur if an Internet application is left running unattended.

\section{The Conundrum of Information Accuracy on the Internet}

Most Web surfers have the mistaken belief that information posted on the Internet must be factual. The Salinger phenomenon is the tendency for online users, especially new users, to assume any information published on the Internet is true [1]. The majority of Web users face this believability or gullibility dilemma when doing research based on the Internet. The general public thinks that most information available on the Web is accurate or authoritative. But Carlson and Repman [1] refute this belief by pointing out:

"It isn't all on the Web, When it is there, it is hard to find, after you find it, it may not be there when you want to return to it, and there is no guarantee concerning the quality that you will find."

The traditional criteria of accuracy applies to all kinds of media including the Web. However, Carlson pointed out that some factors-especially accuracy, authoritatively, objectivity, currency, coverage, and intended audience-deserve more scrutiny.

Kobayashi and Takedai [4] reviewed studies of the growth of the Internet and technologies that are useful for information search and retrieval on the Web. They point out that about $85 \%$ of the Internet users surveyed claim using search engines and search services to find specific information. The same surveys show, however, that users are not satisfied with the performance of the current generation of search engines. The slow retrieval speed, communication delays, and poor quality of retrieved results (e.g., noise and broken links) are commonly cited problems.

Furthermore, they note that the exponential increase in Web sites and information on the Web is contributing to the second most commonly cited problem: users' inability to find the information in a simple and timely manner.

Zhang, Chen, and Zhou [10] point out that building composite Web services can save significant time and cost for developing new applications and enhancing the interoperability and collaboration among Ebusiness partners. They proposes a framework for dynamic and personalized composition of Web services using an approach that integrates not only functional attributes of Web services, but also nonfunctional attributes such as service requirements, quality of service, and the preferences and constraints of individual service consumers.

Dynamic Web service composition is emerging as a new way of empowering E-businesses. Building composite Web services can save extensive time and cost for developing new applications and enhancing the interoperability and collaboration among ebusiness partners [10].

\section{Focus of the Paper}

In the preceding section we have seen the different factors that contribute to improving web services and the quality of service for customer satisfaction. Designing Internet applications that adhere to basic design requirements such as accuracy, authority, objectivity, currency, coverage, intended audience, retrieval speed, fast communication, high quality of retrieved results, information found in a simple and timely manner, interoperability and collaboration with other Internet applications are critical factors that may improve customer satisfaction.

Gomez's [2] studies provide benchmarks for the speed and availability of key Internet transactions performed at the world's largest and most visited companies. Companies should periodically measure their application's performances over time and compare them to their competitors and thus find ways to improve business processes. To help companies improve their Internet application performance over time, Gomez provided a series of indexes measuring similar business processes across multiple organizations. Gomez provided three types of benchmarks designed to help customers understand Internet application:

Performance - Provides an awareness of current performance levels of Internet applications and captures the information needed to create a plan to improve performance;

Consistency - Determines if an Internet application has achieved not only a fast delivery but also delivers a consistent end-user experience as companies begin to execute a performance improvement plan and achieve their short-term objectives; and 
Optimization - Measures the degree to which an Internet application is optimized for service delivery as companies optimize performance processes and technologies to reach long-term strategic goals.

This paper analyzed the data on these three benchmarks (performance measured in response time; consistency and optimization of selected organizations) and, using a statistical linear regression model, predicted which of these benchmarks play a significant role in customer satisfaction as it relates to usage of Internet applications is concerned. Differences between these various benchmark indices across organizations will also be compared to understand if specific benchmark measures are more critical to one type of industry than the other. The hypothesis to test in this preliminary study is whether there is a linear relationship between Web site response time and customer satisfaction with the online transaction experiences. Formally:

$\mathbf{H}_{\mathbf{0}}$ : There is no relationship between Web site response time and satisfaction of online business transaction,

$\mathbf{H}_{1}$ : There is a relationship between Web site response time and satisfaction of online business transaction.

\section{DATA ANALYSIS}

A statistical analysis is used to show if there are any relationships between these benchmarks and the satisfaction of customers when using Internet applications to obtain products and services of their choice. A linear regression model is used to explain the relationship of key factors to quality of service and how these factors make an Internet application a strong tool in improving customer relationship

Data regarding the performance of the Web sites for different industries were collected from the industries of banking, brokerage, credit card, hotel and retail from Gomez.com. Gomez is an Internet management and performance measurement company. The company [2] describes its business mission as follows:

"Gomez is the leading provider of business solutions that help companies achieve and maintain peak performance of their web pages and mission-critical Internet applications."

The performance indices for the five industries as published on the Gomez Web site in December 2005 were used for data analysis. A regression model for each of the five industries was performed. The dependent variable used was success rate of completion of the intended transactions and the independent variable selected is response time of Web site. Gomez used simulated real time transactions for leading companies for each industry in North America. The five regression equations provided coefficients ranging from 0.231 to 0.641 . This means that quick response time of the Websites provided higher success rate ( for every second decrease in response time of a Web site, the success rate of completing a transaction increased anywhere from 0.231 to 0.648 in a scale of 0 to 1 ). Therefore the alternate hypothesis $\mathrm{H}_{1}$ is not rejected.

Table 1. Regression Coefficients

$\begin{array}{llllll}\text { Industry } & \text { Multiple R } & \text { R-Square } & \text { Intercept }\left(\mathbf{b}_{\mathbf{0}}\right) & \left.\text { Co-efficient-(} \mathbf{b}_{1}\right) \text { Time } & \text { P-Value } \\ \text { All five industries } & 0.933 & 0.871 & 100.985 & -0.230 & <.00001 \\ \text { Banking } & 0.954 & 0.910 & 101.935 & -0.316 & <.00001 \\ \text { Brokerage } & 0.867 & 0.751 & 102.444 & -0.453 & <.00001 \\ \text { Credit Card } & 0.954 & 0.910 & 105.063 & -0.648 & <.00001 \\ \text { Hotel } & 0.899 & 0.809 & 100.711 & -0.210 & <.00001 \\ \text { Retail } & 0.965 & 0.930 & 101.217 & -0.231 & <.00001\end{array}$


Table 2. Details per Industry

\begin{tabular}{|c|c|c|c|c|}
\hline \multicolumn{5}{|c|}{ Banking Industry } \\
\hline \multicolumn{5}{|l|}{ Regression Statistics } \\
\hline Multiple R & 0.953923 & & & \\
\hline R Square & 0.909969 & & & \\
\hline Adjusted R Square & 0.903967 & & & \\
\hline Standard Error & 0.360297 & & & \\
\hline \multirow[t]{2}{*}{ Observations } & 17 & & & \\
\hline & Coefficients & Standard Error & $t$ Stat & P-value \\
\hline Intercept & 101.9352 & 0.29025773 & 351.1885 & $<.00001$ \\
\hline \multirow[t]{2}{*}{ Response Time } & -0.3156 & 0.02563162 & -12.313 & $<.00001$ \\
\hline & & Credit Card & Industry & \\
\hline \multicolumn{5}{|c|}{ Regression Statistics } \\
\hline Multiple R & 0.954197 & & & \\
\hline R Square & 0.910492 & & & \\
\hline Adjusted R Square & 0.897705 & & & \\
\hline Standard Error & 0.61799 & & & \\
\hline \multirow[t]{2}{*}{ Observations } & 9 & & & \\
\hline & Coefficients & Standard Error & t Stat & $P$-value \\
\hline Intercept & 105.0628 & 0.886024241 & 118.5778 & $<.00001$ \\
\hline Response Time & -0.64829 & 0.076827188 & -8.43833 & $<.00001$ \\
\hline \multicolumn{5}{|c|}{ Retail Industry } \\
\hline \multicolumn{5}{|l|}{ Regression Statistics } \\
\hline Multiple R & 0.964565 & & & \\
\hline R Square & 0.930386 & & & \\
\hline Adjusted R Square & 0.927485 & & & \\
\hline Standard Error & 0.577239 & & & \\
\hline \multirow[t]{2}{*}{ Observations } & 26 & & & \\
\hline & Coefficients & Standard Error & $t$ Stat & $P$-value \\
\hline Intercept & 101.2168 & 0.284538913 & 355.7223 & $<.00001$ \\
\hline Response Time & -0.23135 & 0.012917336 & -17.9097 & $<.00001$ \\
\hline \multicolumn{5}{|c|}{ Brokerage Industry } \\
\hline \multicolumn{5}{|l|}{ Regression Statistics } \\
\hline Multiple R & 0.866537 & & & \\
\hline R Square & 0.750887 & & & \\
\hline Adjusted R Square & 0.709368 & & & \\
\hline Standard Error & 0.316149 & & & \\
\hline \multirow[t]{2}{*}{ Observations } & 8 & & & \\
\hline & Coefficients & Standard Error & $t$ Stat & P-value \\
\hline Intercept & 102.444 & 0.68672928 & 149.1767 & $<.00001$ \\
\hline Response & -0.45307 & 0.10653642 & -4.2527 & 0.005364 \\
\hline
\end{tabular}




\begin{tabular}{|c|c|c|c|c|}
\hline \multicolumn{5}{|c|}{ Hotel Industry } \\
\hline \multicolumn{5}{|c|}{ Regression Statistics } \\
\hline Multiple R & 0.899385 & & & \\
\hline R Square & 0.808894 & & & \\
\hline Adjusted R Square & 0.791521 & & & \\
\hline Standard Error & 0.423206 & & & \\
\hline \multirow[t]{2}{*}{ Observations } & 13 & & & \\
\hline & Coefficients & Standard Error & $t$ Stat & P-value \\
\hline Intercept & 100.7106 & 0.38964661 & 258.4666 & $<.00001$ \\
\hline Response Time & -0.20992 & 0.03076505 & -6.82347 & $<.00001$ \\
\hline
\end{tabular}

\section{CONCLUSIONS}

This paper explored the importance of factors such as performance, consistency, and optimization on Internet Web-based application and their impact on customer satisfaction, quality of service, and overall customer relationship management. We posited in this preliminary study that quicker response time of Web sites increased the success rate of completing online transactions, which can also increase customer satisfaction, improve profitability and strategic competitive edge of the firm. According to the limited data collected, Web site response time was consistently correlated with success rate of the online transactions for the five industries we studied. The entire regression coefficient was significant with the correct signs. The statistical measures computed for all five industries data aggregated were found to be reasonable indicators of the relationships of the variables (Table 1). Future research will incorporate more explanatory variables with extensive data collection of varieties of companies not included in this study.

\section{REFERENCES}

1. Carlson, R. D., \& Repman, J. (2000). Quality Control and Web Information: Is What I See What I Get? WebNet Journal, 2(4), 9.

2. Gomez benchmarking Indices at http://www.gomez.com/Performance_Strategies/ benchmarking.html

3. Hoffman, D., Grivel, E. \& Battle, L. (2005).Designing software architectures to facilitate accessible Web applications. IBM Systems Journal, 44(3), 467-483.

4. Kobayashi, M. \& Takeda, K. (2000).Information Retrieval on the Web. ACM Computing Surveys, 32(2), 144-150.

5. Li, B. \& Nahrstedt, K. (1999). Control based middleware framework for quality of service applications. IEEE Journal on Selected Areas in Communication, 19(9), 1632-1650.

6. Rada, R., Cargill, C. \& Klensin, J. (1998).Consensus and the Web: Sharing Standards Joint Technical Committee 1, WorldWide Web Consortium Column. Communications of the ACM 41(7), 17-23.

7. Sumra, R. \& Arulaz, D. (2002). Quality of Service for Web Services-Demystification, Limitations, and Best Practice. http://www.developer.com/java/web/article.php/ 2027911

8. Uday S. M.(2004). An analysis of the effects of continuous monitoring controls on e-commerce system performance (2004). Journal of Information Systems, 18(2), 29-47.

9. Yixin D., Joseph L. H. Sujay P. \& Joesph P. B. (2003). Managing Web server performance with AutoTune agents. IBM Systems Journal, 42(1), 136-149.

10. Zhang, D., Chen, M. \& .Z., L. (2005). Dynamic and Personalized Web Services Composition In E-Business. Information Systems Management, 22(3), 50-66. 